\title{
The Gang's All Here: How People Used Games to cope with COVID19 Quarantine
}

\author{
Erica Kleinman \\ emkleinm@ucsc.edu \\ University of California, Santa Cruz \\ Santa Cruz, California
}

\author{
Sara Chojnacki \\ chojnacki.s@northeastern.edu \\ Northeastern University \\ Boston, Massachusetts
}

\author{
Magy Seif El-Nasr \\ mseifeln@ucsc.edu \\ University of California, Santa Cruz \\ Santa Cruz, California
}

\begin{abstract}
In 2020, the rapid spread of COVID-19 forced many people to selfisolate, resulting in struggles with mental health [60], and an increase in gaming [3]. In this paper, we seek to examine how individuals used digital games during the quarantine. We conducted a twotier qualitative study where we used a thematic analysis of tweets to derive questions for an online survey that we distributed. Results of thematic analysis of survey responses identified 15 themes. Some themes confirm previous works' findings, particularly how games are used to increase social connection or distract oneself from unpleasant situations. We also found new themes unique to the quarantine, such as interactions with non-player characters used as a surrogate for real-world interaction and using in-game routines as a substitute to real-world routines lost due to the pandemic. This work discusses the use of games during the pandemic and can be seeds for future studies.
\end{abstract}

\section{CCS CONCEPTS}

- Human-centered computing $\rightarrow$ Empirical studies in HCI.

\section{KEYWORDS}

Games, Gameplay, COVID19, Quarantine, Coronavirus, Connection, Isolation, Positive Emotions, Benefits of Gameplay

\section{ACM Reference Format:}

Erica Kleinman, Sara Chojnacki, and Magy Seif El-Nasr. 2021. The Gang's All Here: How People Used Games to cope with COVID19 Quarantine. In CHI Conference on Human Factors in Computing Systems (CHI '21), May 8-13, 2021, Yokohama, Japan. ACM, New York, NY, USA, 12 pages. https: //doi.org/10.1145/3411764.3445072

\section{INTRODUCTION}

In the early months of 2020, the $S A R S-C o V-2$ virus, commonly known as the coronavirus, and the illness it caused, known as COVID19, spread across the globe at alarming speeds. A highly contagious virus with a death toll of approximately two million world wide, it forced governments to order mandatory quarantines, requiring millions of people to self isolate in their homes, forbidden from leaving or interacting withthose outside the household.

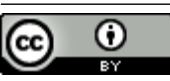

This work is licensed under a Creative Commons Attribution International 4.0 License.

CHI '21, May 8-13, 2021, Yokohama, Japan

(C) 2021 Copyright held by the owner/author(s).

ACM ISBN 978-1-4503-8096-6.

https://doi.org/10.1145/3411764.3445072
By April of 2020, school was online, work was done from home, and many businesses, unable to operate or generate income under the strict quarantine guidelines, were forced to downsize or shut down, resulting in millions of lost jobs. The months that followed saw a notable increase in mental health struggles among the population $[15,41,58,60]$ due to prolonged isolation and uncertainty. At the same time, there was a prominent increase in video game usage $[3,29,40,43]$. Across the globe, games were used to replace in-person events, from weddings [16], to graduations [25, 50], to professional sports [2]. Games were also recommended by professionals to encourage exercise [21,57], educate and train [26], help children on the autism spectrum [39], and as a way to manipulate crowd density in given areas [33, 34].

Before the pandemic, previous work explored the benefits of playing digital games in great detail. There is a clear set of benefits regarding how games can foster social connections and maintain mental well-being through escaping negative circumstances and increasing connection with others $[7,11,54]$. This promise of games as a way to moderate one's mental health has led to the exploration of their use as tools for therapy, treatment, and interventions $[8,13,36,37,49]$. However, while previous work generated extensive knowledge on the benefits (or risks) of games, we acknowledge several limitations of previous work that prompted this study. In particular, previous work was not conducted during a pandemic induced quarantine and was conducted mostly on gaming communities. As a result, it is difficult to say the extent to which existing knowledge may apply to the new context of the COVID-19 pandemic and to a population of people who are new to games. Further, the circumstances of the quarantine may have prompted additional benefits that were not discussed in previous work. It is then both critical and timely to understand the role of gameplay during a quarantine situation such the COVID-19 pandemic, and extend the results discussed by previous studies.

To achieve this goal, we conducted a two-tier qualitative study, where data was collected during the first phase of the pandemic, namely April through July of 2020. In the first tier, in order to reduce researcher bias of how people used games and to ensure that future survey questions reflected the ways in which people were talking about their game usage, we collected 2000 Twitter posts on gaming during quarantine between April 15th and April 22nd 2020. Twitter was chosen due to the accessibility of its API, which allowed us to obtain a large number of posts quickly and efficiently. We conducted a thematic analysis on a subset of them, identifying 12 themes. In the second tier, in order to dig deeper into the details of how people used games and to maximize reach across different participant groups, each theme was converted into an open-answer survey question, and the survey was distributed 
online via Qualtrics and advertised on Facebook between July 1st and August 6th 2020. Facebook was chosen for survey distribution due to the ease of running a recruitment ad on the platform and to target a different audience than Twitter for generalizability. The survey received 130 responses. We then ran a thematic analysis of these responses.

The result of this study presents 15 themes identifying how people used games during the COVID-19 pandemic and the perceived effects of that usage. These results both confirm the persistence of previous works' findings in the new context and reveal new patterns of how people used games to cope that are unique to the quarantine. We organize these themes into four categories:

(1) People are using games to maintain mental well-being

- People are using games to cope with being alone

- People are using games to cope with mental disorders

- People are using games to forget about/escape from the real world and its troubles

- People are using games to replace a routine that was lost due to quarantine

- People are using games to maintain a positive outlook

(2) People are using games to connect with others

- People are using games to connect with distanced loved ones

- People are using games to connect with distanced friends

- People are using games to meet new people

- People are using social media to find people to play with

- People are using games to connect with the people they are quarantined with

(3) People are using games to substitute reality

- People are using games to virtually host events or recreate experiences that cannot occur due to quarantine

- People are using game characters as a substitute for real interaction

- People are using games to recreate real world locations

(4) People are using quarantine as an opportunity to create games

- People are using quarantine time to look into creating games

- People are gamifying everyday activities

There are several implications of these results: (1) a start towards understanding how people used games differently towards, and deriving concrete design requirements for, helping people cope with quarantine circumstances. While the conclusions may seem to be confined to the pandemic, and there appears to be an end to the current pandemic on the horizon, the stress caused by isolation can be felt in other circumstances as well, such as when people must live in isolation for career related reasons (e.g., astronauts), and thus the findings of our study can be used to address how games can help people cope in such situations. (2) This work demonstrates the value of games in human lives, which can be used to situate games as an approach to positively impact lives and help other communities understand their value.

\section{RELATED WORK}

Previous research outlines empirical evidence of benefits and drawbacks of game usage $[18,20,27]$. In this section we discuss previous research specifically outlining the identified overarching benefits of: connectedness, mental health, and the relationship between the two.

\subsection{Fostering Social Connectedness through Games}

A notable benefit of games is the ability to allow people to work together to overcome an objective, which previous work found to generate a sense of connectedness. An example of this is the work of Harris and Hancock [22], who tested the impact of symmetrical and asymmetrical gameplay on social connectedness. They found that asymmetrical gameplay, which fostered interdependence by allowing players to cooperate towards a goal while filling different roles, generated a stronger social connection between players and that these outcomes could be improved through deliberate mechanical design [22]. This resonates with the work of Depping et al. [12], who hypothesized that gameplay afforded people the opportunity to build trust through a shared experience rather than just conversation. They deliberately designed a game for this purpose, and found that it performed better at establishing social ties than a social activity [12]. However, while both studies illustrate the power of games, the games used were designed specifically for this purpose, and both studies were conducted in controlled settings, which constrains the applicability of the findings beyond the game studied.

Vella et al.'s [54] work overcomes this drawback by surveying 446 players about how different modes of play impact psychological needs. Their work was not limited to a given game, and found that a mix of cooperative and competitive play resulted in the highest social capital, and that any kind of collaborative play resulted in higher relatedness than solo play [54]. A more recent online survey by Depping et al. [11] also highlights the interplay between cooperative and competitive play, but found that cooperative play had less impact on social connectedness than previous work suggested. They suggest that cooperative play can be regarded as more important for establishing a new relationship than for an established one [11]. This work shows that, even among mainstream games, the ability to share an experience can allow people to feel connected with one another. However, it also illustrates that this phenomenon is dynamic and that context (in this case the length of the relationship) is an important factor in what kind of experience players will seek together.

Because of the opportunity they offer to share an experience or develop a bond, many players are motivated to play games with the specific goals of forging and maintaining friendships [10, 54]. More than half of the respondents in Zhang and Kaufman's [62] study of World of Warcraft (Blizzard, 2004) players discussed real life friends and family in relation to gameplay while $48 \%$ indicated that they trusted the people they had met in game. These findings are somewhat in sync with those of Park et al. [42], who conducted a data driven study of a massive multiplayer online role playing game (MMORPG). They found that, while achievement features were predictive of new player retention, social features were a better predictor of retention for high level players. However, Park et al.'s study does not offer an explanation for why the players found the social components so appealing [42]. 
Other literature, however, may offer an explanation. Sanderson et al. [47] studied the draw of Fortnite among student athletes, and found that many were motivated to play because it was an opportunity to connect with existing friends and teammates, as well as meet new people from other teams or beyond their sport entirely.

Sanderson et al.'s findings also resonate with two separate studies that found that the promise of a shared activity with friends was one of the most prominent motivations for picking up multiplayer online battle arena (MOBA) games [38, 52]. Further, Tyack et al. [52] discovered that there were significant differences in what MOBA players valued in teammates who were friends vs. strangers. Notably, skilled play and complementary roles and characters were valued more during play with strangers, while positive attitude and enjoyable conversation were of higher value during play with friends [52]. This implies that there is a difference in the gameplay experience when one is playing with friends, in which players are more focused on connecting through conversation than in-game achievements. The survey results also demonstrated that many individuals were able to make friends through gameplay, although the strength of the friendship varied [52].

It is important to note that gaming is no longer bound to the computer or a console. Recent years have seen the rise of location based games that add a new dimension, physical co-location, to multiplayer gaming. One of the most prominent examples of this is the game Pokemon Go (Niantic, 2016), which offers unique experiences for collaborative play with both friends and strangers [5]. In addition to the social capital affordances offered by traditional online games, the game (and others like it) also increases a sense of community belonging through exploration of one's neighborhood and conversations with strangers $[28,53]$.

The ability games afford to connect with and make new friends allows people to use games to build and maintain contact with welcoming and safe online communities [52]. This is illustrated well by the work of Cole and Griffiths on the social landscape of MMORPGs [10]. They found that two fifths of respondents to their online survey would often discuss issues with online friends that they would not discuss with friends in real life [10]. A similar finding emerged from a series of interviews with male gamers conducted by Vella et al. [55]. Participants expressed that online friendships offered a safe space to talk about real-world problems. Because they were viewed as non-judgemental, and otherwise removed from the crisis, they were perceived by participants to be able to offer more perspective. They also found that players who developed such a bond were close enough to discern each others' moods based only on behavior [55]. These benefits resonate with the work of Bargh [4], who found that individuals were more easily able to express their true selves during online interactions.

While all of the work highlighted the value of game-based online communities, they also illustrated and recognized that these communities have their limits. In the case of Tyack et al.'s work on MOBAs [52], players stated that they would discuss topics with in-game friends they would not discuss in real life. However, many respondents expressed that in-game friendships were fleeting, and would end if one party stopped playing, or if a disagreement occurred [52]. However, this phenomenon occurred in a setting in which players could experience both real life and in-game interactions. During a quarantine, real life interaction is severely limited. Thus, it is important to know the extent to which these trends persist given the changed context.

\subsection{Bullying and toxicity act as obstacles to the social benefits of gaming}

While our goal is to highlight the benefits of gaming, it should also be noted that there are obstacles to fostering connections in multiplayer games. Specifically, female players are often forced to hide their gender in order to avoid abuse $[52,56]$. Further, toxic behavior, such as trolling, aggression, and negativity, can have a notable impact on how individuals view a game's community $[11,51,52]$ and can be a factor that drives people to stop playing [52]. Despite these concerns, many individuals still turn to games for the chance to connect with others. Ultimately, it may be that the perceived benefits outweigh the apparent risks. This may be especially true during a quarantine period, when no other interactions are available. Alternatively, lack of other sources of entertainment may drive people to torment others in-game more than they otherwise would. Either way, previous work didn't explore this context.

\subsection{Games provide a way to relieve negative emotions or stress}

Research on the connection between games and mental well-being has found that many people use games to relieve negative emotions or recover from stressful situations [30, 44]. In an interview study with 71 online gamers, Hussain and Griffiths [23] found that approximately one third of the participants played MMORPGs because the game helped them relieve their negative emotions. In some cases, these negative emotions were difficult to relieve through other means, i.e. it was easier to fight digital monsters than yell at people [23]. A similar result emerged in the previously discussed work of Vella et al. with male gamers [55], where online gaming was described as cathartic, and a productive way to deal with real-world frustrations.

The opportunity games afford for stress relief and improving one's mood is prominent enough that previous work explored how games are able to afford this experience. In a laboratory study, Rieger et al. [45] found that in-game success, such as winning a race, results in increased mood repair, but that needs-satisfaction only impacted enjoyment, and had no effect on mood. Bae et al. [1] conducted an experiment in which they had bored and stressed players use in-game items and found that item usage had an impact on mood management. Specifically, bored players were able to relieve their boredom through functional items while stressed players were able to relieve stress through decorative items [1]. While both studies identified mechanical elements that afford stress relief, there is also potential for a game's aesthetic elements to achieve this goal. For example, Rogers and Nacke [46] explored the impact of game audio on a player's ability to relax and de-stress, and provided design suggestions based on existing examples. They did not, however, present empirical results to back up their claims. 


\subsection{Games provide a (potentially risky) respite or escape from unpleasant situations}

Similar to stress relief, games also afford a mode of escape, offering a respite from unpleasant situations. For example, in a series of interviews, Carras et al. [7] found that military veterans often used games as a form of self-medication or therapy due to gameplay's ability to act as a distraction. Participants discussed using games to replace other, risky behaviors, such as alcoholism or drug abuse [7] Iacovides and Mekler's [24] qualitative study of the role of games during difficult life experiences also found that games can be a much needed respite for people. Further, they found that participants often sought gameplay experiences that were unlikely to generate additional discomfort or stress, and therefore focused on those that were familiar or repetitive [24].

However, it is impossible to talk about games as an escape without bringing up the risks of unhealthy escapism [31, 32, 61]. In their work with Taiwanese adolescents, Wan and Chiou $[58,59]$ found that unhealthy escapism through gaming is more likely to stem from the relief of dissatisfaction or escape of an unpleasant reality over the pursuit of satisfaction. While the sample for Wan and Chiou's research consists primarily of Taiwanese gamers, the risk of games acting as an obstacle to well-being is also acknowledged by the respondents in Iacovides and Mekler's study [24]. This suggests a degree of generalizability, and indicates that players who seek solace in games are aware of the inherent risk of addiction.

As with the other benefits of gaming, escapism as a benefit, and its potential risks, have never been evaluated in the context of a global pandemic or a mass quarantine. Being unable to engage in other activities, combined with a stressful situation in the world at large, is likely to result in escapism through gaming. However it is unknown how the changed context will impact people's perceptions of excessive gaming. While those in previous work were cognizant of the risks of escaping through gameplay [24], perceptions of the perceived risks, and how individuals feel about their own escapism, may be different when there are few other options.

\section{METHODOLOGY}

This work seeks to answer the following question: how have people used games to cope with COVID19 quarantine? To answer this question, we designed a two-step study that was conducted during the pandemic. The first step of the study was a thematic analysis of tweets, collected in April of 2020 during which time much of the United States was under strict stay-at-home orders with nonessential businesses closed and non-essential activities banned. The themes that resulted from this analysis were then used to create a survey that was distributed online. The survey was distributed in July of 2020, during which time much of the United States was beginning to open back up, and many outdoor, non-essential activities were permitted if conducted with small numbers and face coverings. IRB approval was acquired at the onset of the work and survey participants consented anonymously via an IRB-approved online consent form. All participants were required to be residing within the united states.

\subsection{Twitter Analysis}

It was of utmost importance that our survey questions reflect how people were thinking about, talking about, and using games. Thus, we began by conducting an initial thematic analysis of social media posts, focusing specifically on Twitter, due to the platform's large number of public and accessible posts.

2000 tweets were collected using Twitter's free API between April 15th and April 22nd 2020. We began to see saturation in the tweets around 1200 and thus chose to stop collecting at 2000 . The API was set to collect tweets that included the keyword "quarantine" alongside one or more of "Videogame", "Videogames", "Game", "Games", "Xbox", "Playstation", "Nintendo", "Animal Crossing", "Club Penguin", "Final Fantasy", "World of Warcraft", "League of Legends", “Overwatch", "Fortnite", "Roblox", "Jackbox", "Call of Duty", "Esports", "Dota", "Hearthstone", "Persona", "Minecraft", or "Twitch". Specific game titles were chosen for the search by the research team based on what games were popular, what games were mentioned in the news about quarantine, and what games were recently released. All of the collected tweets were public and any tweet obviously posted by a bot was removed by the researchers during an initial review of the data set.

We acknowledge that this is not an all encompassing search, however, we feel that the tweets that were collected embodied a representative sample of the kinds of social media posts people were making about gaming during quarantine. We were not specifically targeting new gamers at this point, however, these keywords selected any tweets related to games and quarantine, and thus, our sample was not restricted to only heavy gamers.

Following the protocol for thematic analysis [17], two researchers, separately, examined the collected tweets and each developed an initial list of themes. The two researchers then reconvened, discussed, and combined their individual lists. The resulting combined list consisted of twelve themes (see Table 1). In order to validate the themes, the researchers each, separately applied them to a subset of the collected data consisting of 300 tweets (approximately $10 \%$ of the data set, following established protocols for IRR [6]) that were determined to be representative of the entire set. Inter-rater reliability was calculated using Cohen's kappa [9] and resulted in a score of .84, indicating very strong agreement [35].

\subsection{Online Survey}

We then created a survey consisting of demographic questions and twelve open-response questions corresponding to the 12 Twitter themes. The survey questions are detailed in Table 2, if a participant answered "yes" to the yes/no question, they were provided with a text entry box and asked to elaborate. We chose the survey method over other approaches due to its efficiency given the timeliness of this research as it was conducted during the pandemic. The survey was posted online via Qualtrics and advertised on Facebook (chosen due to the ease with which we could run a recruitment ad) from July 1st to August 6th 2020. Participants who completed the survey were entered into a raffle for one of three 100 dollar gift cards. Data was collected anonymously, with each participant assigned a random ID number.

The short answer responses were analyzed via thematic analysis. Two researchers separately examined the entire data set and 
Table 1: The 12 themes that resulted from the Twitter analysis, and examples tweets for each theme. Bold themes reflect benefits discussed in previous work.

\begin{tabular}{|c|c|}
\hline Theme & Example \\
\hline $\begin{array}{l}\text { Talking about one's daily life or relationships inside a } \\
\text { game world as if they were real }\end{array}$ & $\begin{array}{l}\text { "Now that we're in quarantine Animal Crossing is the the only way } i \\
\text { can go outside, But funnily enough everyone there hates me..... Just like } \\
\text { real life" }\end{array}$ \\
\hline $\begin{array}{l}\text { Using a game environment to simulate a real-world } \\
\text { experience }\end{array}$ & "Attending a virtual concert on club penguin was very quarantine $2020 "$ \\
\hline Recreating real-world locations within games & $\begin{array}{l}\text { "@HamiltonMusical after seeing the show and now being stuck in } \\
\text { quarantine, I decided to take my shot at making the stage in Minecraft, } \\
\text { (snapshot 20w16a) \#Hamilton \#Minecraft" }\end{array}$ \\
\hline $\begin{array}{l}\text { Video games as a tool to stay connected with } \\
\text { friends, family, and loved ones }\end{array}$ & $\begin{array}{l}\text { "Best part of quarantine is being able to turn my Xbox on at any time of } \\
\text { day and having a dozen friends online..." }\end{array}$ \\
\hline Video games as a tool to meet new people & $\begin{array}{l}\text { "Who plays Overwatch on PC? Trying to get some games in later????? } \\
\text { I'm bored out of my mind in quarantine. trying to find more games to } \\
\text { play with people on PC!!! What is everyone playing nowadays!?!?!?!" }\end{array}$ \\
\hline Video games as a way to pass time & $\begin{array}{l}\text { "Get up, Breakfast, Video games, Having lunch, Read, Eat potato chips, } \\
\text { Sleep, Get up again, Thank you quarantine, My life was never so sched- } \\
\text { uled like this" }\end{array}$ \\
\hline Video games to help with mental stability & $\begin{array}{l}\text { "my quarantine experience is a lot like that Jason Statham movie 'Crank', } \\
\text { except I have to keep playing and beating video games without stopping } \\
\text { or else I'll fall into a covid-inspired crippling existential crisis" }\end{array}$ \\
\hline $\begin{array}{l}\text { People taking quarantine as an opportunity to get into } \\
\text { game development }\end{array}$ & "decided to make my own board game so... \#quarantine" \\
\hline $\begin{array}{l}\text { Finding ways to gamify quarantine lives or discussing } \\
\text { quarantine activities as if they were a game }\end{array}$ & $\begin{array}{l}\text { "Let's play a really fun quarantine game. Someone leave a bottle of wine } \\
\text { at my front door, ring the door bell, and take off. I'll try and guess who } \\
\text { left it" }\end{array}$ \\
\hline $\begin{array}{l}\text { Video games as a way to connect, interact, and } \\
\text { spend time with those quarantined with you }\end{array}$ & $\begin{array}{l}\text { "interesting quarantine moments. Learned to play Minecraft with the } \\
\text { kids. Built a big house together. Battled skeletons. It was wholesome." }\end{array}$ \\
\hline $\begin{array}{l}\text { Connecting game achievements specifically to the quar- } \\
\text { antine }\end{array}$ & $\begin{array}{l}\text { "I beat final fantasy } 9 \text {. This is a feat that I couldn't accomplish at } 12 \text { but } \\
\text { I could at 32. It truly is a strange time, this quarantine" }\end{array}$ \\
\hline Gaming habits specifically influenced by quarantine & $\begin{array}{l}\text { "I never used to play video games and now all I do is play Fortnite or } \\
\text { that FIFA demo.. quarantine life!" }\end{array}$ \\
\hline
\end{tabular}

constructed individual lists of themes until they reached saturation. The two researchers then reconvened and went over their separate lists, combining them into a single list. In order to assess the validity of the themes, the researchers separated again and each independently applied the combined themes to a third of the data set. Inter-rater reliability was calculated using Cohen's Kappa [9], and the result was .86, indicating very strong agreement [35]. One researcher then coded the entire data set.

\section{RESULTS}

Given the research question, we focus on the qualitative analysis of the short answer responses and present a set of themes detailing the ways in which people used games to cope with COVID19 quarantine. The thematic analysis resulted in a final set of 15 themes categorized into 4 categories (see table 3). Some themes relate to the benefits of games outlined in previous work, as shown in the table, confirming their persistence in the context of quarantine while shedding light on the details of their relevance. New themes reveal unique patterns in game usage sparked by quarantine. The final theme set is described below.

\subsection{Participants}

The survey received 130 complete responses. 77 respondents identified as male, 51 as female, and two as non-binary. Participant age varied quite a bit with the largest group $(n=44)$ being between 18 and 25. The distribution for self-reported time spent gaming before and during quarantine can be seen in Figure 1. 27\% reported playing five or less hours of games a week prior to the quarantine, with the majority of the sample (62\%) reportedly playing 10 hours or less before quarantine. Only $12 \%$ reported playing more than 20 hours a week before quarantine. However, 33\% of participants reported playing 20 hours a week or more during quarantine, and only $5 \%$ reported playing five or less. Additionally, $76 \%$ of all respondents, $70 \%$ of those who had played five or fewer hours prior to quarantine, reported an increase in weekly time spent playing video games during quarantine. This indicates that our sample includes individuals who would not have been considered heavy gamers prior to quarantine. Further, this indicates that our sample includes people who have increased their video game usage during the quarantine. 
Table 2: The 12 short answer questions used in the online survey. If a participant responded "yes" to any question, they were prompted in a follow up question to elaborate on the experience. Each question in the survey was developed from one of the Twitter themes identified in the first step of the study.

\begin{tabular}{|c|l|}
\hline & Question \\
\hline 1. & $\begin{array}{l}\text { During Quarantine, have you attended any type of gathering or event (such as a party, graduation, concert, } \\
\text { etc...) that was held inside of a video game? }\end{array}$ \\
\hline 2. & $\begin{array}{l}\text { Have you felt that video game entities (such as objects, characters, or locations) have become a replacement } \\
\text { for daily activities or interactions during quarantine? }\end{array}$ \\
\hline 3. & $\begin{array}{l}\text { During quarantine, have you been involved in the recreation of real-world locations inside of a video game } \\
\text { environment (such as Minecraft)? }\end{array}$ \\
\hline 4. & $\begin{array}{l}\text { During quarantine, have you played online games with friends, family, or loved ones that you are not physically } \\
\text { quarantined with? }\end{array}$ \\
\hline 5. & Have you met new people through games during the quarantine? \\
\hline 6. & Do you feel as though you are spending a significant amount of time playing games during the quarantine? \\
\hline 7. & $\begin{array}{l}\text { Do you feel as though playing games has helped you to maintain a positive outlook or feel positive emotions } \\
\text { during quarantine? }\end{array}$ \\
\hline 8. & $\begin{array}{l}\text { During the quarantine, have you felt a desire, or have you taken steps, to get into game development? (Either } \\
\text { digital or analog) }\end{array}$ \\
\hline 9. & $\begin{array}{l}\text { During quarantine, have you looked for opportunities or felt the desire to create games out of daily activities } \\
\text { or chores or household objects? For example: Rearranging phone apps to create words or puzzles, making a } \\
\text { game out of social media messages or texts, or gamifying chores or unpleasant activities? }\end{array}$ \\
\hline 10. & $\begin{array}{l}\text { If you are quarantined with other people, have you played video games with them, either online or in person, } \\
\text { while physically co-located? }\end{array}$ \\
\hline 11. & $\begin{array}{l}\text { Do you feel as though being quarantined has resulted in in-game accomplishments? (Such as: gaining skill, } \\
\text { achieving goals, receiving trophies, etc...) }\end{array}$ \\
\hline 12. & $\begin{array}{l}\text { Have your gaming habits or preferences changed during the quarantine? For example: are you playing different } \\
\text { games, during different hours, or are you playing games now when you did not before? }\end{array}$ \\
\hline
\end{tabular}
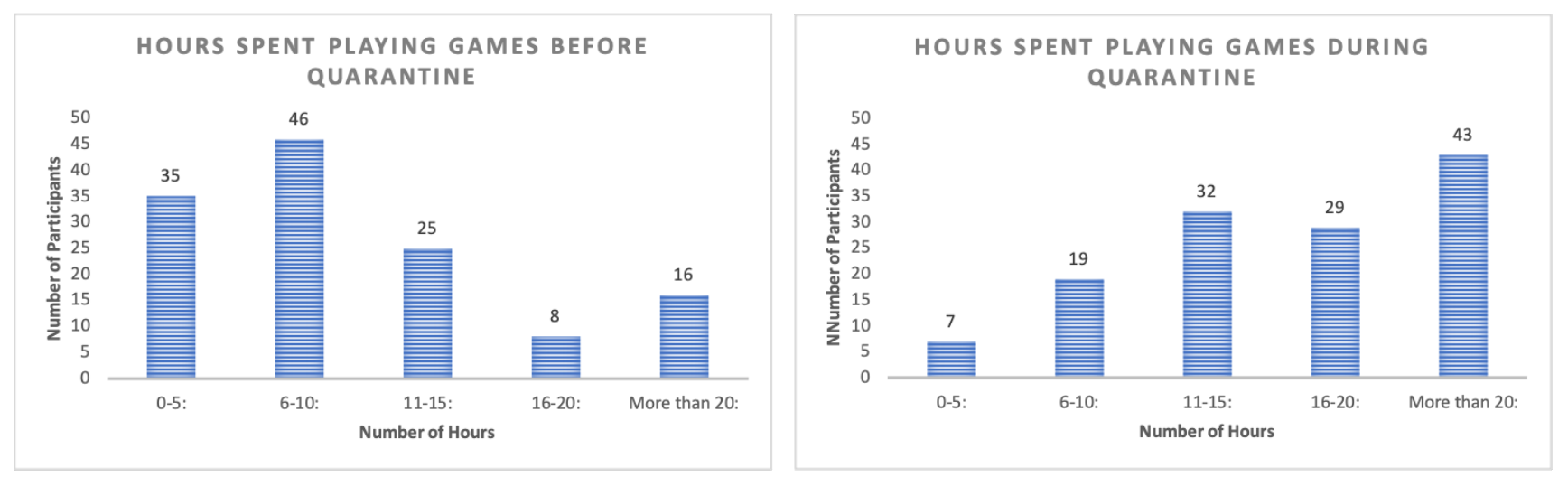

Figure 1: Distribution of hours spent gaming before (a) and during (b) quarantine for 130 respondents in the data set.

\subsection{Category 1: People are using games to maintain mental well-being}

4.2.1 Theme 1.1: People are using games to cope with being alone. This theme emerged from moments when people mentioned that games helped them make up for, cope with, and feel better about being lonely. This theme emerged from 10 statements from 10 different participants, 5 of whom are casual to moderate gamers. 8 out of 10 participants reported an increase in game time during quarantine. While this theme was not discussed by the majority of the respondents, those who did speak about it often did so at length.

This theme lay at the intersection between connections and mental well-being as participants often indicated that the connection they felt with others through games was what allowed them to drive off loneliness. We chose to include it in this category due to the emphasis from participants that this was directly connected to 
Table 3: The 15 themes that resulted from the qualitative analysis of the survey data, sorted into 4 categories, along with the number of instances of this theme (i.e. how many question responses discussed it), and the number of participants who discussed it (a participant could discuss a given theme in more than one question response). Bolded themes are not present in previous work, and italicised themes are partially present in related work.

\begin{tabular}{|c|c|c|}
\hline Theme & Instances & Participants \\
\hline \multicolumn{3}{|l|}{ Category 1: Mental Well-Being } \\
\hline 1.1: People are using games to cope with being alone & 10 & 10 \\
\hline 1.2: People are using games to cope with mental disorders & 10 & 8 \\
\hline 1.3: People are using games to forget about/escape from the real world and its troubles & 60 & 54 \\
\hline 1.4: People are using games to replace a routine that was lost due to quarantine & 191 & 100 \\
\hline 1.5: People are using games to maintain a positive outlook & 86 & 67 \\
\hline \multicolumn{3}{|l|}{ Category 2: Connections } \\
\hline 2.1: People are using games to connect with distanced loved ones & 17 & 17 \\
\hline 2.2: People are using games to connect with distanced friends & 96 & 69 \\
\hline 2.3: People are using games to meet new people & 42 & 37 \\
\hline 2.4: People are using social media to find people to play with & 6 & 5 \\
\hline 2.5: People are using games to connect with the people they are quarantined with & 52 & 46 \\
\hline \multicolumn{3}{|l|}{ Category 3: Substituting Reality } \\
\hline 3.1: People are using games to host events that cannot occur due to quarantine & 16 & 14 \\
\hline 3.2: People are using game characters as a substitute for real interaction & 16 & 15 \\
\hline 3.3: People are using games to recreate real world locations & 14 & 13 \\
\hline \multicolumn{3}{|l|}{ Category 4: Creating Games } \\
\hline 4.1: People are using quarantine time to look into creating games & 18 & 14 \\
\hline 4.2: People are gamifying everyday activities & 6 & 5 \\
\hline
\end{tabular}

maintaining their mental well-being, for example: "I was losing my mind at the beginning of quarantine because of the stay at home order. I am an extrovert but I worried about getting sick. So gaming has been a safe haven" (participant 7). This theme resonates with previous work on games providing an opportunity to connect or make friends and games providing a community, however it differs as the isolation experienced during a quarantine is imposed by an outside force.

While previous work emphasized this effect in connection to online social gaming, respondents from our survey also discussed it in relation to single player gameplay, for example: "I haven't really been leaving my apartment since the pandemic started. But I can play animal crossing and know that I have tasks to do everyday and an island full of animal villagers who are happy to see me. They help me feel less lonely since I mainly only see one other actual person in real life" (participant 117). This discovery that people have found that non-player characters can bring them a sense of connectedness, or ease loneliness is not prominent in previous work and may be a sensation sparked by the isolation of quarantine.

4.2.2 Theme 1.2: People are using games to cope with mental disorders. This theme emerged from moments when people specifically mentioned that the act of gaming was helping them cope with a specific mental disorder. We note that we did not conduct any medical measurements of participants' mental states and acknowledge that it is possible that a respondent may say that a game is helping their mental health when it is, in reality, having no effect. This theme emerged from 10 statements from 8 respondents, 5 of whom reported more than 10 hours of gameplay a week prior to quarantine. Similar to the previous theme, those who discussed this often did so at length.

This theme specifically refers to people mentioning mental disorders and how they believe that games have helped them. It relates to findings in previous work regarding how people use games to manage their own mental disorders [7]. For example: "it definitely lets me escape the anxiety and depression I've been dealing with for years. Quarantine definitely made them worse, but gaming lets me forget for a while" (participant 93). In one particular case, a participant explicitly stated that they may not have survived without games: "I would probably be dead right now without video games" (participant 125).

4.2.3 Theme 1.3: People are using games to forget about/escape from the real world and its troubles. This theme emerged from participants stating that games were helping them keep their mind off things, distract themselves, or experience a "happier" world. This theme emerged from 60 question responses from 54 participants, of whom 36 reported playing fewer than 10 hours of games before quarantine. This is the fourth most prominent theme in the set and directly relates to findings from previous work. Examples of statements that this theme applies to are "I play the games a few hours a day, enter all the contests and compete for prizes. I like the idea of forgetting what is really going on with me" (participant 35) and "Especially when nothing in my city was open, video games were a fun escape from how boring and uneventful normal life was becoming..." (participant 18). 
4.2.4 Theme 1.4: People are using games to replace a routine that was lost due to quarantine. This theme emerged from statements in which participants described a game as giving them something to do during the day, or providing them with a schedule or routine. This theme was the most prominent one in the data set, emerging from 191 separate statements from 100 participants. Of that set, 61 reported less than 10 hours of game time a week prior to quarantine, and 80 reported an increase in game time during quarantine.

This benefit was not discussed in previous work, as it has likely emerged as a unique result of the pandemic robbing people of their daily schedules through mandatory quarantine. This has left them to look for new ways to structure, and maintain control over, their time; for example: "Having a daily cycle of gaming scheduled is very "work-like" because I make myself do it no matter how I feel. It helps me keep a rhythm" (participant 54). There were two different ways in which games performed this role:

- The game itself is the routine: When the act of playing games becomes a daily routine to fill a void or pass the time. For example "Play game $3 \mathrm{~h}$ a day is part of my schedule" (participant 39) or "While I do play more and spend more on game related purchases, I believe it is due more to having more time available than before. With nothing else to do or anywhere to go I spend a generous amount of time online. I enjoy my time online and so I'm happy to have some extra time to friends with friends and be able to talk to people while still remaining in quarantine" (participant 75). This was the more common occurrence.

- The game provides the routine: When in-game activities become a daily routine. For example: "In animal crossing there are daily tasks- shake the trees to catch the wasps, hit the rocks for resources and money, harvest the money tree and plant a new one, find the fossils on your island, talk to your villagers. I'm very bad as maintaining a routine without something external reinforcing it, so having this daily routine in game helps a lot..." (participant 37).

4.2.5 Theme 1.5: People are using games to maintain a positive outlook. This theme emerged from participants who used games to stay positive or feel better about their situation. This theme was the third most prominent in the data set, emerging from 86 separate statements from 67 participants. Of the 67 participants, 43 reported fewer than 10 hours of game time a week prior to quarantine, and 56 reported an increase in game time during quarantine.

While the kinds of negative circumstances encountered by players in previous work typically had a defined ending and did not interfere with their ability to engage in other activities, the COVID19 quarantine continued for months with no definitive end, and resulted in cutting off most people's access to any activity outside their home. Further, the circumstances causing this were out of most people's control. This may have resulted in different kinds of boredom, distress, or hopelessness than what were encountered in previous work, thus requiring people to find a way to maintain a sense of hope or positivity.

By analyzing code applications, we identified three ways in which games were able to generate a positive outlook, the first two reflect Self Determination Theory [14], specifically to relatedness and competence:
- Games allow you to connect with others: For example: "I'm happy I like playing video games because it makes the quarantine less awful. And games that I play with other people give me a feeling of socialization" (participant 83).

- Games give you a goal to work towards and a sense of accomplishment: For example: "I can feel accomplishment when I finish a game or do something. I feel like life continues. I look forward to "work hours" ending so "game hours" can start. This would suck if I didn't have games. Movies and TV are so passive I'd get so bored if that is all I had" (participant 76).

- Games provide something to look forward to: For example: "definitely offers something to look forward to after work since I can't really do in-location activities. If I did not have games during quarantine it would have been much more difficult" (participant 92).

\subsection{Category 2: People are using games to connect with others}

4.3.1 Theme 2.1: People are using games to connect with distanced loved ones. This theme emerged from participants who used games to connect with loved ones, i.e. family or very close friends, whom they were not co-located with. This theme was discussed 17 times by 17 participants. Of that 17,12 reported 10 or fewer hours of games a week prior to quarantine. 14 out of the 17 participants who discussed this theme reported an increase in game time during quarantine.

This theme relates directly to previous work on how people are able to connect through games. Because this theme relates to distanced individuals, it predominantly referred to games with online features, i.e. "I found out my niece got animal crossing. she lives in another state so I got to go over to her island and become her hero by giving her all sorts of stuff that she didn't have. I felt so good for Days" (participant 127). Further, participants discussed how this was a way to still be a part of loved ones' lives even while separated by quarantine orders, i.e. "I play games with my sister and my brother. It doesn't quite fill the void the same as being able to visit them in person. But it keeps me in contact with them and it's a way to show that I can still be in their life" (participant 34).

4.3.2 Theme 2.2: People are using games to connect with distanced friends. While the previous theme emerged from discussions of games being used to connect with distanced loved ones, this theme pertains to the use of games to connect with distanced friends, acquaintances, classmates, or co-workers. This theme emerged from 96 separate question responses from 69 participants, making it the second most prominent theme in the data set. 39 of these participants reported fewer than 10 hours of gameplay a week prior to quarantine, and 55 reported an increase in game time during quarantine.

Unlike the previous theme, the relationships discussed in these statements may not be highly established, but were still important enough to maintain through gameplay. Again, this relates to previous work on how people can connect through gameplay, and pertains to online play due to the distanced nature of those involved. An example of such a statement is: "I play online games with my co-worker friends. One of them highly recommended the Nintendo 
Switch console, and helped me set it up. I like playing games with them because I can see how they are in another way. Sometimes we even work on our own islands in Animal Crossing or journey in Legend of Zelda: Breath of the Wild and call each other on the phone to talk about what we're working on. It's another way to feel close to each other" (participant 130).

4.3.3 Theme 2.3: People are using games to meet new people. This theme emerged from respondents who mentioned that they made new friends through games, a theme that is prevalent in previous work. This theme emerged from 42 separate question responses from 37 participants, indicating that it was discussed in answers to more than one question and making it the sixth most prominent theme. 21 of these participants reported fewer than 10 hours of gameplay a week prior to quarantine, and 29 reported an increase in game time during quarantine.

In some cases, this occurred because people had teamed up to pursue in-game goals, a phenomenon discussed in previous work. A goal could be clearly defined, such as defeating a boss "I attended raids and raid events in Pokemon go. These involve strangers joining groups to battle Pokemon" (participant 50). Participants also discussed meeting friends of friends through gaming, rather than complete strangers, i.e. "Friends of friends have joined our gaming group for fallout and fortnite" (participant 113). Some respondents discussed how they continued to play with the people they met, e.g., "I met them within World of Warcraft and Destiny. And Monster Hunter: World. Since meeting them, we have raided and played in large groups together and connected over Discord" (participant 34).

4.3.4 Theme 2.4: People are using social media to find people to play with. This theme emerged from a pattern in the data where people mentioned using social media to find and connect with people who played the same games and, in most cases, play together. Only 5 participants discussed this theme, and only 1 of them discussed it more than once. This makes it one of the least prominent themes in the data-set. 2 participants reported playing fewer than 10 hours of games a week prior to quarantine, and 3 reported an increase in weekly game time during quarantine.

Although previous work emphasized the benefit of games as a way to build an online community, the importance of social networks was not prominent. It may be that the quarantine induced isolation pushed more people to seek out gameplay companions, i.e. "I chatted with a fellow member of a Facebook fallout 4 group that im a part of to share gaming information" (participant 108) and"I met a handful of gamers on Twitter. I had responded to a tweet that it was difficult to find people to play with and I was just invited. Merely by chance! I'm still in the midst of my first asynchronous board game online with them" (participant 97).

4.3.5 Theme 2.5: People are using games to connect with the people they are quarantined with. This theme emerged from respondents who mentioned connecting through gameplay with those they were quarantined with. This theme emerged from 52 separate question responses from 46 participants, making it the fifth most prominent theme. 32 of the 46 participants reported 10 or fewer hours of gameplay a week prior to quarantine, and 37 reported an increase in game time during quarantine.
This theme is not unique to quarantine, as discussed in previous work. Responses that related to this theme discussed both co-located roommates and family members. Examples of statements that related to this theme are: "I enjoy quality time with my 8 year old son more so thanks to gaming. The time I have been able to play with him has increased so we have utilized it. Playing games with him most definitely lifts both of our moods during quarantine" (participant 53) and "Instead of being in far corners of house not interacting. Jackbox.tv has been fun sharing game time and what we know of each other" (participant 124).

\subsection{Category 3: People are using games to substitute reality}

These themes relate to phenomena discussed in previous work, for example, players have been known to host major life events in game (such as funerals e.g. $[19,48]$ ). However, we argue that these themes are new and distinct from previous work as they emerge from survey responses that highlight how the practice is informed and motivated by specific circumstances of quarantine, i.e. events being held in game specifically because they cannot be held in reality, whereas previous work highlights events held in game because the attending community is unique to the game environment.

4.4.1 Theme 3.1: People are using games to virtually host events or recreate experiences that cannot occur due to quarantine: This theme emerged from situations in which people spoke about attending events, or engaging in some form of organized activity, inside of a game environment. The events discussed in responses related to this theme differ from previous work in that they are primarily events that could no longer occur in reality due to the pandemic. This theme emerged from 16 question responses by 14 participants. 6 of the 14 played 10 or fewer hours of games a week prior to quarantine, and 10 of them reported an increase in time spent gaming during quarantine.

There were three types of events that emerged in the data:

- Public Events: Such as concerts or graduations, for example: "I attended the Travis Scott concert they had within fortnite. It was organized really well and it gave us a nice concert type situation even though we couldn't attend one in person" (participant 10).

- Private Events: Such as birthday parties or weddings, for example: "We had a little birthday / graduation celebration for my friend Axel in Animal Crossing New Leaf. He graduated with his bachelor's degree the same day as his birthday. We held a little ceremony that happened to coincide with the bug catching tournament" (participant 31).

- Regular Events: Referring to events or activities that occurred regularly prior to quarantine, such as a game night or vacations. For example: "Boardgame meetup in Tabletop Simulator. Normal Meetup group" (participant 76).

4.4.2 Theme 3.2: People are using game characters as a substitute for real interaction: This theme emerged from participants describing their relationships with game characters, or how they interacted with them, as a replacement for real-world social interaction. This theme was discussed in 16 question responses by 15 participants. 
8 of the 15 played 10 or fewer hours of games a week prior to quarantine, and 12 of them reported an increase in game time during quarantine.

While isolation exists in normal world contexts, the complete inability to engage in any real life social interaction is largely unique to a quarantine period. Thus, this theme appears to be the result of a need to maintain a sense of normal connection when human contact is almost impossible. Examples of this theme indicate that participants (to some degree) view game characters as if they are real, i.e. "Can't be around people. The people in the games are my friends" (participant 142) and see interaction with them as a surrogate for real interaction, such as "I fully immerse myself in video games so I feel like the people are talking to me. They make me feel as if I'm having human interaction and it makes me feel normal" (participant 10). In some cases, participants indicated that they found this kind of interaction to be preferable to real human interaction, as it involved less pressure and afforded them more control of the situation. An example of this can be seen in: "I've been playing animal crossing new horizons daily because you have an island full of characters that you get attached to who are always so excited when you talk to them. I'm an introvert by nature but talking with my villagers every day gives me a chance to socialize on my terms without me feeling like I'm being overwhelmed" (participant 43).

4.4.3 Theme 3.3: People are using games to recreate real world locations: This is another theme that may be unique to quarantines, as the desire to recreate a real world location appears to be born from an inability to be there, i.e. "I built my summer camp in Animal Crossing. I was supposed to start working there again this summer but it was cancelled. I did it mostly myself, but friends gave me items" (participant 98) and "My friends and I recreated a Ralph's because we would hang out by there all the time bc there is a park near by" (participant 3). This theme was discussed in 14 question responses by 13 participants. 6 of the 14 played 10 or fewer hours of games a week prior to quarantine and 10 of them reported an increase in game time during quarantine.

Often, building was a group activity, that gave friends and family an objective to work towards together, i.e. "I have been building a castle with my friends over online play and we were just bored and wanted to play with each other so that's why we did that" (participant 61) and "I have worked with my sister, who lives with me, on some buildings like the Eiffel Tower, some skyscrapers, and various pyramids. We were prompted to build these together because we were bored and these gave us a goal to reach. My role was as an equal with my sister, we both worked on it equally." (participant 19).

\subsection{Category 4: People are using quarantine as an opportunity to create games:}

Neither theme in this category relates to previous work.

4.5.1 Theme 4.1: People are using quarantine time to look into creating games: This theme emerged from responses to question eight (see Table 2) in which people discussed how the time and frequent gaming afforded by quarantine had sparked an interest in pursuing game development. This theme emerged from 18 question responses from 14 participants. 10 of the 14 reported playing 10 or fewer hours of games a week prior to quarantine, and 14 of them reported an increase in game time during quarantine.

This does not relate to the findings of previous work, as it is specific to the quarantine context. Examples of statements this theme applies to are: "I have started making a board game because I have lot of ideas." (participant 101) and "I might get into making games. I have a lot of time now and if it's something that I can get into right now I can see myself keeping at it because of what videos games does to enhance my life" (participant 123).

4.5.2 Theme 4.2: People are gamifying everyday activities: This theme emerged from responses to question nine (see Table 2) in which participants discussed the tendency to gamify day to day or unpleasant activities during quarantine in an attempt to make them more enjoyable. This theme emerged from responses from only 6 question responses from 5 participants, making it one of the least prominent themes in the set. 3 out of the 6 reported playing 10 or fewer hours of games a week prior to quarantine, and 4 reported an increase in game time during quarantine.

Like the previous theme, this is quarantine specific and does not relate to benefits of gaming discussed in previous work. In some cases, the gamification was a way to inject fun into, and therefore keep people focused on, productive activities, i.e. "Me and my sister raced to see who could do chores quicker and the winner got a smoothie. " (participant 55) or "Trying to stack the dishes at peak effectiveness in the dishwasher..." (participant 122).

\section{DISCUSSION}

Our results shed light on how people have used games to maintain mental well-being and foster connections in order to cope with quarantine, confirming the relevance of previous work and highlighting new themes.

Previous work highlighted numerous ways in which games can help people manage their mental well-being [1, 7, 23, 24]. The themes in category 1 , confirm that these benefits remain relevant during the quarantine, as games continue to help people manage mental illness and escape from unpleasant situations. However, the most prominent theme in the entire data set is theme 1.4, which relates to games providing a routine. This benefit was not brought up in previous work, as it is likely unique to the quarantine, a period in which many have been stripped of school or work related routines. The prominence of this theme suggests that games can help people manage mental well-being not only through escape but also through replacement, by providing surrogates for normalcy. This phenomenon can also be seen in relation to theme 1.1, related to coping with loneliness through online and NPC interaction, and the entirety of theme category 3 , related to substituting reality with in game locations, events, and interactions. This indicates that the ability to generate a sensation of normalcy through virtual replacement of real world activities may be a key way that games can help people cope with quarantine, and similar isolating circumstances.

Previous work also highlights the ability to connect with others as a benefit of gaming [12,22, 54]. Overall, survey responses confirmed that this benefit persists even within the context of quarantine, as highlighted by the themes in category 2 . While none of the themes in this category are exclusively new findings, confirming 
their persistent relevance during the unique context of quarantine is an important stepping stone to future work that may examine the phenomenon in more detail. For example, the emphasis on seeking connections may be connected to the construct of relatedness from Self Determination Theory (SDT) [14]. Previous work has used SDT to understand the benefits of games [54], and this indicates that SDT may still be a relevant lens to examine game usage during quarantine. Additionally, while all of the themes in this category appear, or partially appear, in previous work, it is worth noting the general absence of discussions of toxicity, recognized in previous work as an obstacle to connecting through games [51, 52]. It is possible that the quarantine context has turned people's attention to the perceived benefits of their gameplay so much so that any negative experiences are forgotten. Future work will be necessary to examine the impact of quarantine on in-game toxicity.

Finally, theme category 4, which revealed that people were using quarantine as an opportunity to start creating games, encompasses two themes not related to previous work. These themes were largely restricted to responses to the two questions that asked participants about creating games during quarantine. A potential avenue for future research is to examine the extent to which game development is the result of more time, inspired by playing more games, or fueled by the sense of accomplishment that comes from creating something.

\subsection{Limitations}

We acknowledge that there may be a bias in our results in that people who use certain social media sites may be of similar mindsets, and that by not recruiting from other internet communities (such as Reddit or Tumblr) we may have missed some information. Although we acknowledge this as a limitation, the themes collected from Twitter became survey questions that resonated relatively well with respondents from Facebook, implying that there is likely a common ground between online communities. Additionally, we acknowledge that 130 people is not a statistically significant sample size. However, given the qualitative focus of this work we argue that this does not invalidate the results, which we present as insightful and useful starting points for future research. We also acknowledge that we only collected survey responses from participants residing within the United States, and that people quarantined in other countries, with different policies and infection rates, may have different experiences. We argue that this does not invalidate the results of this work, which can act as a foundation for future studies comparing the use of games during quarantine across borders.

\section{CONCLUSION}

As COVID19 spread across the world in the early months of 2020, millions of people were confined to their homes. With the stress of an unprecedented quarantine bearing down on them, many people turned to games as a way to foster social connections and maintain mental well-being. The goal of this work was to explore the ways in which people used games to cope with quarantine.

To this end, we conducted a two-step study. The first step was a thematic analysis of collected tweets that discussed gaming in the context of quarantine. This analysis resulted in 12 themes with an IRR of .84 that were then used to create a 12-question open-answer survey. In the second step, the survey was distributed online, and through thematic analysis of the responses we were able to derive a set of 15 themes organized into four categories with an IRR of .86. These themes reveal the ways in which quarantined individuals leveraged games as a tool to cope with their circumstances. We discussed these findings and how they relate to previous work, confirming the continued relevance of past findings as well as highlighting new patterns in behaviors as discussed by participants. Further, we discuss insights into why participants have chosen games over other mediums, how they feel about their gameplay, and implications for future research and design.

The results of this study inspire several avenues for future work. As discussed, the themes presented here offer opportunities to explore the use of games as a tool to cope with quarantine and isolation. We envision this work as a stepping stone for future research that may examine these themes, and their impact on quarantined players, in more detail.

\section{REFERENCES}

[1] Joonheui Bae, Sang Jin Kim, Kyung Hoon Kim, and Dong-Mo Koo. 2019. Affective value of game items: a mood management and selective exposure approach. Internet Research (2019)

[2] Kendall Baker. 2020. NASCAR leads the virtual sports charge amid coronavirus outbreak. https://www.axios.com/coronavirus-virtual-sports-nascar-videogames-a25392ae-8ee6-4739-bdc3-2514b85562dd.html

[3] Matthew Ball. 2020. The Impact of COVID-19 on Video Gaming and Our Virtual Lives. https://www.matthewball.vc/all/covidgames

[4] John A Bargh, Katelyn YA McKenna, and Grainne M Fitzsimons. 2002. Can you see the real me? Activation and expression of the "true self" on the Internet. Journal of social issues 58, 1 (2002), 33-48.

[5] Arpita Bhattacharya, Travis W Windleharth, Rio Anthony Ishii, Ivy M Acevedo, Cecilia R Aragon, Julie A Kientz, Jason C Yip, and Jin Ha Lee. 2019. Group interactions in location-based gaming: A case study of raiding in pokémon go. In Proceedings of the 2019 CHI Conference on Human Factors in Computing Systems. $1-12$.

[6] John L Campbell, Charles Quincy, Jordan Osserman, and Ove K Pedersen. 2013. Coding in-depth semistructured interviews: Problems of unitization and intercoder reliability and agreement. Sociological Methods \& Research 42, 3 (2013), 294-320.

[7] Michelle Colder Carras, Anna Kalbarczyk, Kurrie Wells, Jaime Banks, Rachel Kowert, Colleen Gillespie, and Carl Latkin. 2018. Connection, meaning, and distraction: A qualitative study of video game play and mental health recovery in veterans treated for mental and/or behavioral health problems. Social Science \& Medicine 216 (2018), 124-132.

[8] T Atilla Ceranoglu. 2010. Video games in psychotherapy. Review of General Psychology 14, 2 (2010), 141-146.

[9] Jacob Cohen. 1960. A coefficient of agreement for nominal scales. Educational and psychological measurement 20, 1 (1960), 37-46.

[10] Helena Cole and Mark D Griffiths. 2007. Social interactions in massively multiplayer online role-playing gamers. Cyberpsychology \& behavior 10, 4 (2007), 575-583.

[11] Ansgar E Depping, Colby Johanson, and Regan L Mandryk. 2018. Designing for friendship: Modeling properties of play, in-game social capital, and psychological well-being. In Proceedings of the 2018 Annual Symposium on Computer-Human Interaction in Play. 87-100.

[12] Ansgar E Depping, Regan L Mandryk, Colby Johanson, Jason T Bowey, and Shelby C Thomson. 2016. Trust me: social games are better than social icebreakers at building trust. In Proceedings of the 2016 Annual Symposium on ComputerHuman Interaction in Play. 116-129.

[13] Fernando Fernández-Aranda, Susana Jiménez-Murcia, Juan J Santamaría, Katarina Gunnard, Antonio Soto, Elias Kalapanidas, Richard GA Bults, Costas Davarakis, Todor Ganchev, Roser Granero, et al. 2012. Video games as a complementary therapy tool in mental disorders: PlayMancer, a European multicentre study. Journal of Mental Health 21, 4 (2012), 364-374.

[14] Marylène Gagné and Edward L Deci. 2005. Self-determination theory and work motivation. Journal of Organizational behavior 26, 4 (2005), 331-362. 
[15] Junling Gao, Pinpin Zheng, Yingnan Jia, Hao Chen, Yimeng Mao, Suhong Chen, Yi Wang, Hua Fu, and Junming Dai. 2020. Mental health problems and social media exposure during COVID-19 outbreak. Plos one 15, 4 (2020), e0231924.

[16] Aron Garst. 2020. The pandemic canceled their wedding. So they held it in Anima Crossing. https://www.washingtonpost.com/video-games/2020/04/02/animalcrossing-wedding-coronavirus/

[17] Helen Gavin. 2008. Thematic analysis. Understanding research methods and statistics in psychology (2008), 273-282.

[18] James Paul Gee. 2007. Good video games+ good learning: Collected essays on video games, learning, and literacy. Peter Lang.

[19] Martin Ross Gibbs, Marcus Carter, Michael Arnold, and Bjorn Nansen. 2013. Serenity Now bombs a World of Warcraft funeral: Negotiating the morality, reality and taste of online gaming practices. AoIR Selected Papers of Internet Research (2013).

[20] Isabela Granic, Adam Lobel, and Rutger CME Engels. 2014. The benefits of playing video games. American psychologist 69, 1 (2014), 66.

[21] Amri Hammami, Basma Harrabi, Magni Mohr, and Peter Krustrup. 2020. Physical activity and coronavirus disease 2019 (COVID-19): specific recommendations for home-based physical training. Managing Sport and Leisure (2020), 1-6.

[22] John Harris and Mark Hancock. 2019. To asymmetry and beyond! Improving social connectedness by increasing designed interdependence in cooperative play. In Proceedings of the 2019 CHI Conference on Human Factors in Computing Systems. 1-12.

[23] Zaheer Hussain and Mark D Griffiths. 2009. The attitudes, feelings, and experiences of online gamers: A qualitative analysis. CyberPsychology \& Behavior 12, 6 (2009), 747-753.

[24] Ioanna Iacovides and Elisa D Mekler. 2019. The Role of Gaming During Difficult Life Experiences. In Proceedings of the 2019 CHI Conference on Human Factors in Computing Systems. 1-12.

[25] Evan Imber-Black. 2020. Rituals in the Time of Covid 19: Imagination, Responsiveness and the Human Spirit. Family Process (2020)

[26] Mohd Javaid, Abid Haleem, Raju Vaishya, Shashi Bahl, Rajiv Suman, and Abhishek Vaish. 2020. Industry 4.0 technologies and their applications in fighting COVID-19 pandemic. Diabetes \& Metabolic Syndrome: Clinical Research \& Reviews (2020).

[27] Joseph Kahne, Ellen Middaugh, and Chris Evans. 2009. The civic potential of video games. The MIT Press.

[28] Jihyun Kim, Kelly Merrill Jr, and Hayeon Song. 2020. Probing with Pokémon: Feeling of presence and sense of community belonging. The Social Science Journal $57,1(2020), 72-84$.

[29] Orsolya Király, Marc N Potenza, Dan J Stein, Daniel L King, David C Hodgins, John B Saunders, Mark D Griffiths, Biljana Gjoneska, Joël Billieux, Matthias Brand, et al. 2020. Preventing problematic internet use during the COVID-19 pandemic: Consensus guidance. Comprehensive Psychiatry (2020), 152180.

[30] Mehmet Kosa and Ahmet Uysal. 2020. Four Pillars of Healthy Escapism in Games: Emotion Regulation, Mood Management, Coping, and Recovery. In Game User Experience And Player-Centered Design. Springer, 63-76.

[31] Daria J Kuss and Mark D Griffiths. 2012. Online gaming addiction in children and adolescents: A review of empirical research. fournal of behavioral addictions 1, 1 (2012), 3-22.

[32] Daria J Kuss, Jorik Louws, and Reinout W Wiers. 2012. Online gaming addiction? Motives predict addictive play behavior in massively multiplayer online roleplaying games. Cyberpsychology, Behavior, and Social Networking 15, 9 (2012), 480-485.

[33] Samuli Laato, AKM Najmul Islam, and Teemu H Laine. 2020. Did location-based games motivate players to socialize during COVID-19? Telematics and Informatics (2020), 101458.

[34] Samuli Laato, Teemu H Laine, and AKM Islam. 2020. Location-Based Games and the COVID-19 Pandemic: An Analysis of Responses from Game Developers and Players. Multimodal Technologies and Interaction 4, 2 (2020), 29.

[35] J Richard Landis and Gary G Koch. 1977. The measurement of observer agreement for categorical data. biometrics (1977), 159-174.

[36] Ho Ming Lau, Johannes H Smit, Theresa M Fleming, and Heleen Riper. 2017. Serious games for mental health: are they accessible, feasible, and effective? A systematic review and meta-analysis. Frontiers in psychiatry 7 (2017), 209.

[37] Jinhui Li, Yin-Leng Theng, and Schubert Foo. 2014. Game-based digital interventions for depression therapy: a systematic review and meta-analysis. Cyberpsychology, Behavior, and Social Networking 17, 8 (2014), 519-527.

[38] Rees Morris and Sarah Wiseman. 2019. Choosing a Side: How do Players Pick a Game when Entering the MOBA Genre?. In Extended Abstracts of the Annual Symposium on Computer-Human Interaction in Play Companion Extended Abstracts. 573-579.

[39] Antonio Narzisi. 2020. Handle the autism spectrum condition during Coronavirus (COVID-19) stay at home period: Ten tips for helping parents and caregivers of young children.

[40] Maria Nicola, Zaid Alsafi, Catrin Sohrabi, Ahmed Kerwan, Ahmed Al-Jabir, Christos Iosifidis, Maliha Agha, and Riaz Agha. 2020. The socio-economic implications of the coronavirus pandemic (COVID-19): A review. International journal of

surgery (London, England) 78 (2020), 185.
[41] World Health Organization et al. 2020. Mental health and psychosocial considerations during the COVID-19 outbreak, 18 March 2020. Technical Report. World Health Organization.

[42] Kunwoo Park, Meeyoung Cha, Haewoon Kwak, and Kuan-Ta Chen. 2017. Achievement and friends: key factors of player retention vary across player levels in online multiplayer games. In Proceedings of the 26th International Conference on World Wide Web Companion. 445-453.

[43] Andrew M. Phelps. 2020. Gaming fosters social connection at a time of physical distance. https://theconversation.com/gamingfosters- social-connection-at-a-time- of-physical-distance- 135809 ?fbclid $=$ IwAR3b3R05qFwOveVmAOqt5tOStq3LalBzVFG-teQImcGIb8GG6TiPrZS0PVQ

[44] Leonard Reinecke. 2009. Games and recovery: The use of video and computer games to recuperate from stress and strain. Fournal of Media Psychology 21, 3 (2009), 126-142.

[45] Diana Rieger, Tim Wulf, Julia Kneer, Lena Frischlich, and Gary Bente. 2014. The winner takes it all: The effect of in-game success and need satisfaction on mood repair and enjoyment. Computers in Human Behavior 39 (2014), 281-286.

[46] Katja Rogers and Lennart E Nacke. 2017. Exploring the Potential of Game Audio for Wellbeing.. In PGW@ CHI PLAY.

[47] Jimmy Sanderson, Blair Browning, and Hank DeHay. 2020. " It's the Universal Language:" Investigating Student-Athletes' Use of and Motivations for Playing Fortnite. Journal of Issues in Intercollegiate Athletics (2020)

[48] Olivier Servais. 2015. Funerals in the 'World of Warcraft': religion, polemic, and styles of play in a videogame universe. Social Compass 62, 3 (2015), 362-378.

[49] Avani Shah, Kyle R Kraemer, Cho Rong Won, Sheila Black, and Will Hasenbein. 2018. Developing digital intervention games for mental disorders: a review. Games for health journal 7, 4 (2018), 213-224.

[50] TodayShow. 2020. See the graduation ceremony these fourth-graders made in Minecraft. https://www.today.com/parents/kid-creates-graduation-minecraftafter-school-closure-t176475

[51] Selen Türkay and Sonam Adinolf. 2019. Friending to flame: How social features affect player behaviours in an online collectible card game. In Proceedings of the 2019 CHI Conference on Human Factors in Computing Systems. 1-12.

[52] April Tyack, Peta Wyeth, and Daniel Johnson. 2016. The appeal of moba games: What makes people start, stay, and stop. In Proceedings of the 2016 Annual Symposium on Computer-Human Interaction in Play. 313-325.

[53] Kellie Vella, Daniel Johnson, Vanessa Wan Sze Cheng, Tracey Davenport, Jo Mitchell, Madison Klarkowski, and Cody Phillips. 2019. A sense of belonging: Pokemon GO and Social Connectedness. Games and Culture 14, 6 (2019), 583-603.

[54] Kellie Vella, Daniel Johnson, and Leanne Hides. 2015. Playing alone, playing with others: Differences in player experience and indicators of wellbeing. In Proceedings of the 2015 annual symposium on computer-human interaction in play. 3-12.

[55] Kellie Vella, Daniel Johnson, and Jo Mitchell. 2016. Playing support: Social connectedness amongst male videogame players. In Proceedings of the $2016 \mathrm{An}$ nual Symposium on Computer-Human Interaction in Play Companion Extended Abstracts. 343-350.

[56] Kellie Vella, Madison Klarkowski, Selen Turkay, and Daniel Johnson. 2020. Making friends in online games: gender differences and designing for greater social connectedness. Behaviour \& Information Technology 39, 8 (2020), 917-934.

[57] Ricardo Borges Viana and Claudio Andre Barbosa de Lira. 2020. Exergames as Coping Strategies for Anxiety Disorders During the COVID-19 Quarantine Period. Games for Health fournal (2020).

[58] Chin-Sheng Wan and Wen-Bin Chiou. 2006. Psychological motives and online games addiction: Atest of flow theory and humanistic needs theory for taiwanese adolescents. CyberPsychology \& Behavior 9, 3 (2006), 317-324.

[59] Chin-Sheng Wan and Wen-Bin Chiou. 2006. Why are adolescents addicted to online gaming? An interview study in Taiwan. Cyberpsychology \& behavior 9, 6 (2006), 762-766.

[60] Cuiyan Wang, Riyu Pan, Xiaoyang Wan, Yilin Tan, Linkang Xu, Roger S McIntyre, Faith N Choo, Bach Tran, Roger Ho, Vijay K Sharma, et al. 2020. A longitudinal study on the mental health of general population during the COVID-19 epidemic in China. Brain, behavior, and immunity (2020).

[61] Shinichi Yamaguchi. 2020. The Relationship Between Time Spent Playing Mobile Games and Wellbeing. Available at SSRN 3568469 (2020).

[62] Fan Zhang and David Kaufman. 2017. Massively multiplayer online role-playing games (MMORPGs) and socio-emotional wellbeing. Computers in Human Behavior 73 (2017), 451-458. 